\title{
The climate reconstruction in Shandong Peninsula, northern China, during the last millennium based on stalagmite laminae together with a comparison to $\delta^{18} \mathrm{O}$
}

\author{
Qing Wang ${ }^{1}$, Houyun Zhou ${ }^{2}$, Ke Cheng ${ }^{1}$, Hong $\mathrm{Chi}^{1}$, Chuan-Chou Shen ${ }^{3}$, Changshan Wang ${ }^{1}$, and Qianqian Ma ${ }^{1}$ \\ ${ }^{1}$ Coast Institute of Ludong University, Yantai 264025, China \\ ${ }^{2}$ School of Geography, South China Normal University, Guangzhou 510631, China \\ ${ }^{3}$ High-precision Mass Spectrometry and Environment Change Lab (HISPEC), Department of Geosciences, National Taiwan \\ University, Taipei 10617, Taiwan, ROC
}

Correspondence to: Qing Wang (schingwang@ 126.com) and Houyun Zhou (hyzhou@gig.ac.cn)

Received: 31 July 2015 - Published in Clim. Past Discuss.: 2 October 2015

Revised: 15 January 2016 - Accepted: 1 February 2016 - Published: 8 April 2016

\begin{abstract}
Stalagmite ky1, with a length of $75 \mathrm{~mm}$ and the upper part (from top to $42.769 \mathrm{~mm}$ depth) consisting of 678 laminae, was collected from Kaiyuan Cave in the coastal area of Shandong Peninsula, northern China, located in a warm temperate zone in the East Asia monsoon area. Based on high-precision dating with the $\mathrm{U}-{ }^{230} \mathrm{Th}$ technique and continuous counting of laminae, the 1st and 678th laminae have been confirmed to be $\mathrm{AD} 1894 \pm 20$ and $1217 \pm 20$ from top to bottom, respectively. By the measurement of laminae thickness and $\delta^{18} \mathrm{O}$ ratios, we haved obtained the time series data of thickness of laminae and $\delta^{18} \mathrm{O}$ ratios from $\mathrm{AD} 1217 \pm 20$ to $1894 \pm 20$, analyzed the climaticenvironmental meaning of variations in the thickness of laminae, which have a good correspondence with the cumulative departure curve of the drought-waterlog index in the historical period. The results show that, in the $\sim 678$ years from AD $1217 \pm 20$ to $1894 \pm 20$, both the thickness of the laminae and the degree of fluctuation in the thickness of the laminae of stalagmite ky1 have obvious stages of variation and are completely synchronized with the contemporaneous intensity of the summer monsoons and precipitation as time changed. There is a negative correlation between the thickness of the laminae and the summer monsoon intensity and precipitation. There is a positive correlation between the degree of fluctuation in the thickness of the laminae and both the intensity of the summer monsoons and the precipitation. Therefore, for the Kaiyuan Cave in the coastal area of both the warm temperate zone and the East Asia monsoon area,
\end{abstract}

the variations in the thickness of the laminae are not only related to the change in the climatic factors themselves but also related to the degree of climatic stability. In the coastal area belonging to the warm temperate zone and the East Asia monsoon area, the climate change between the LIA (Little Ice Age) and the MWP (Medieval Warm Period), in addition to less precipitation and low temperatures (a type of dry and cold climate), also shows an obviously decreasing trend in the degree of climatic stability.

\section{Introduction}

Calcareous speleothems, which have advantages for precisely dating and high-resolution sampling, are becoming one of the best geological record carriers for major climate changes (Burns et al., 2003; Cheng et al., 2009; Dykoski et al., 2005; Genty et al., 2003; Fairchild et al., 2006; Wang et al., 2001, 2008; Qin et al., 1999; Yuan et al., 2004) and highresolution reconstruction of the paleoclimate and paleoenvironment (Committee on Surface Temperature Reconstructions for the Last 2000 Years and National Research Council, 2006; Fleitmann et al., 2003; Hou et al., 2003; McDermott et al., 2001; Paulsen et al., 2003; Tan et al., 2003; Tan, 2007; Wang et al., 2005; Zhang et al., 2008). In addition to the most widely used carbon $(\mathrm{C})$ and oxygen $(\mathrm{O})$ stable isotopes and trace elements, laminae and the growth rate of stalagmites could also be used as proxies for the paleoclimate environment. However, different authors have very different climate 
and environment interpretations relative to thickness of laminae based on different stalagmites from different climatic regions. For instance, the stalagmite laminae were confirmed as annual laminae in the earliest studies (Baker et al., 1993), the structure of the laminae reflected the intensity of the ancient rainfall (Baker et al., 1999), and there was a positive correlation between the growth rate of stalagmites and precipitation (Brook et al., 1999). However, there was a negative correlation between the growth rate of stalagmites and precipitation (Proctor et al., 2000, 2002), there was a responsive relationship between the growth rate of the stalagmites and the winter temperature (Frisia et al., 2003), and the growth rate of the stalagmites was influenced by the vegetation density on the top of the cave (Baldini et al., 2005). There was a well-understood relationship between the speleothem growth rate and climate (Baldini, 2010; Mariethoz et al., 2012). The situation is more complex in humid and semi-humid regions because other factors such as drip rate, atmospheric $P_{\mathrm{CO} 2}$ in the cave and the seasonality of the climate may also affect speleothem growth rates (Cai et al., 2011; Duan et al., 2012). The investigation of stalagmite laminae in the middle reach of the Yangtze River indicates that the thickness of stalagmite laminae may be regarded as a substitute index for the summer monsoon intensity in East Asia (Liu et al., 2005). There was a good response relationship between the variations in the thickness of the laminae and the variations in rainfall (Tan et al., 1997; Ban et al., 2005). There was a response relationship between the growth rate of the stalagmites and the temperature in summer; therefore, the thickness of the laminae may be regarded as a substitute index for East Asia monsoon intensity (Tan et al., 2004). The $\delta^{18} \mathrm{O}$ record of ZJD-21 indicates that $\delta^{18} \mathrm{O}$ in the stalagmite was influenced mainly by the amount of rainfall and/or the summer/winter rainfall ratio, with lower values corresponding to wetter conditions and/or more summer monsoon rains (Kuo et al., 2011). The stalagmite $\delta^{18} \mathrm{O}$ record represented local-regional moisture change and the monsoon rainfall (Li et al., 2011). The growth rate and the observed temperature have a significant positive correlation (Tan et al., 2013).

The upper part of ky1 (from the top to a depth of 42.769 , $0-42.769 \mathrm{~mm}$ ) consists of 678 continuous clearly transmitting annual laminae, because the transmitting laminae of the stalagmite ky 1 are very similar to the annual laminae of Shihua Cave in Beijing and have all of the typical characteristics of the latter laminae, which consist of so-called northern type laminae (Zhou et al., 2010). There are clearly very thin opaque laminae between stalagmite laminae, but the calcite laminae are thick and transmitting between the stalagmite laminae (Tan et al., 1999, 2002). Because stalagmite ky1, with a very short length, has no trace of any weathering, the stalagmite may have stopped growing not long ago. Its deposition time may be the past several centuries or one millennium, which has recorded the climatic-environmental information of the Shandong Peninsula since the late MWP (Medieval Warm Period), including the late MWP, the whole
LIA (Little Ice Age) and the early CWP (Current Warm Period) (Lamp, 1965, 1972; Matthews, 2005; Ogilvie and Jónsson, 2001). In this research, on the basis of high-precision dating with the U-230 Th technique, we have observed and measured the thickness of the laminae and dated all of the laminae in the upper part of stalagmite ky1, obtained and researched the time series data on thickness of laminae and compared these data with the time series data for both the oxygen $(\mathrm{O})$ stable isotope value and the drought-waterlog index, and we discussed the climatic and environmental evolution of the coastal part of the warm temperate zone as well as the East Asia monsoon area since the LIA, especially in the transition periods of MWP/LIA and LIA/CWP.

\section{Geological setting and sample description}

Stalagmite ky1 was collected in AD 2008 from Kaiyuan Cave $\left(36^{\circ} 24^{\prime} 32^{\prime \prime}[\mathrm{U}+2033] \mathrm{N}, 118^{\circ} 02^{\prime} 05^{\prime \prime}[\mathrm{U}+2033] \mathrm{E}\right)$ in western Shandong Peninsula, the coastal area of northern China (Figs. 1, 2). The cave is located in the northwest hilly area of Mount Lu in Zibo City, Shandong Province, with an elevation of $175 \mathrm{~m}$ above sea level (a.s.l.) (Fig. 2). As the largest peninsula in China, the Shandong Peninsula is located between the Bohai Sea and the Yellow Sea, and in its western region, the Middle Cambrian Zhangxia formation (mainly the oolitic shale, shale in clip to thin-layer limestone, oolitic limestone, algal clot limestone) and the Ordovician Badou formation and Gezhuang formation (mainly the graydark gray thick layer of mud, wafer-thin limestone, dolomitic limestone and marl) are widely distributed with a thickness of $24-238 \mathrm{~m}$, including the lower section integrated with the Gezhuang Group and the upper section disconformity in contact with the Carboniferous Benxi formation (Shandong Provincial Bureau of Geology-Minerals, 1991), which are the main components of the Mount $\mathrm{Lu}$, Yi, and Meng with the highest elevations (1108, 1031 and $1150 \mathrm{~m}$, respectively). According to field investigation, the landforms of the carbonate rocks in mountainous caves are well developed, and there are many cave outcroppings on the surface. Secondary carbonate sedimentary bodies are developing well with typical morphological characteristics.

Kaiyuan Cave developed in the dolomite of the Ordovician Zhifangzhuang formation with a total thickness of the strata of approximately $110 \mathrm{~m}$. The total length of the cave is $1280 \mathrm{~m}$, the overall distribution is a northwest-southeast strike with twists and turns, and the space width inside the cave is generally 2 to $8 \mathrm{~m}$ and can be up to $30 \mathrm{~m}$. At the top of the cave, the surface of the bedrock is covered by soil with a general thickness of $50-80 \mathrm{~cm}$, and the thickest soil was more than $1.0 \mathrm{~m}$. The soil types are calcareous rocky soil and drab soil (Soil and Fertilizer Workstation of Shandong Province, 1994). The area of Kaiyuan Cave is currently influenced by both summer and winter monsoons with annual precipitation of $\sim 620 \mathrm{~mm}$ and an annual mean temperature of $\sim 13^{\circ} \mathrm{C}$, 


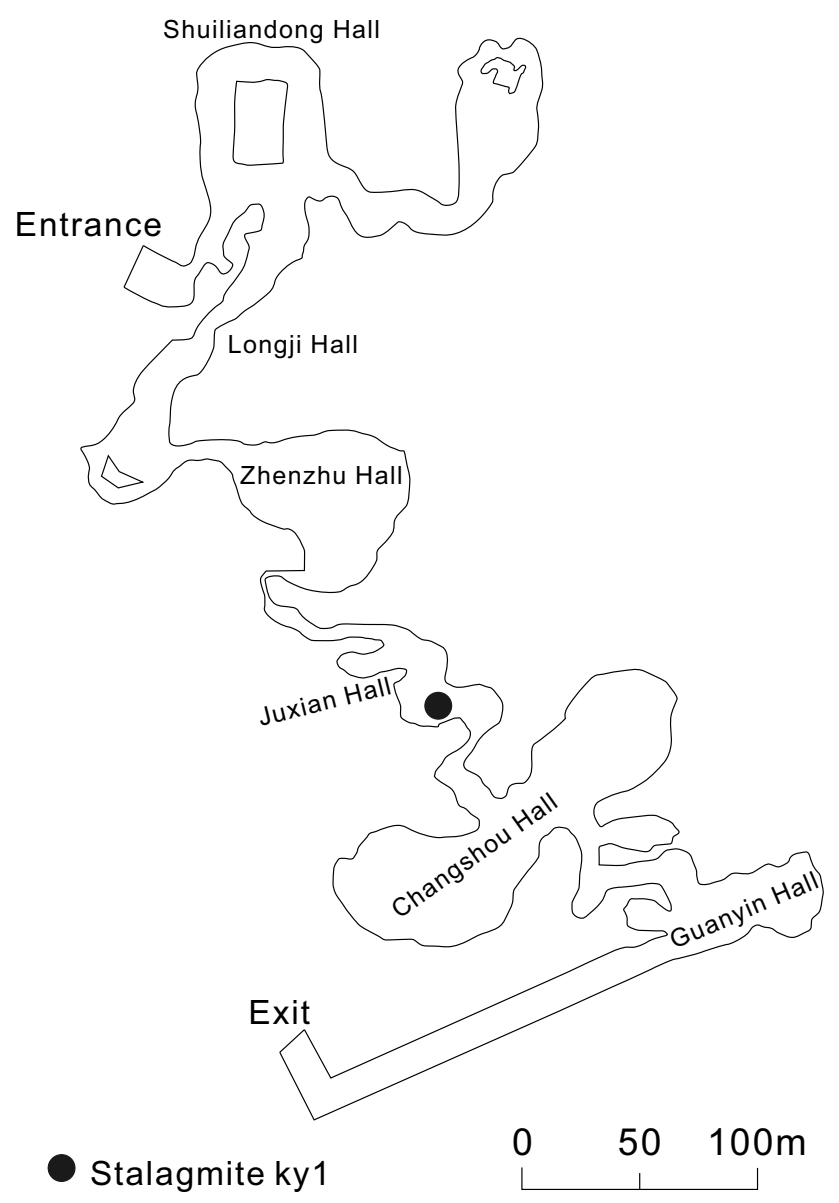

Figure 1. The map of Kaiyuan Cave. The black point is the location where we collected the sample in the cave. The cave has an entrance and an exit and consists of six small halls.
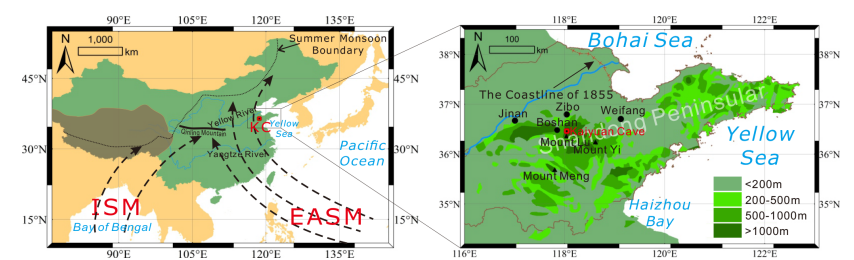

Figure 2. Location of Kaiyuan Cave and Shandong Peninsula in monsoonal China. KC: Kaiyuan Cave $\left(36^{\circ} 24^{\prime} 32^{\prime \prime}[\mathrm{U}+2033] \mathrm{N}\right.$, $\left.118^{\circ} 02^{\prime} 05^{\prime \prime}[\mathrm{U}+2033] \mathrm{E}\right)$. ISM: India summer monsoon; EASM: East Asia summer monsoon. The dashed black thin line indicates the northwestern boundary of the Asian summer monsoon. The dashed black lines with arrows indicate the routes of the summer monsoon. The dashed black lines with arrows on the left indicate the routes of the summer monsoon. The brown area is the QinghaiTibet Plateau. The green and brown area is China, and the yellow area is the other area.

and summer monsoons prevail during July and August, contributing to half of the annual precipitation (Fig. 3).
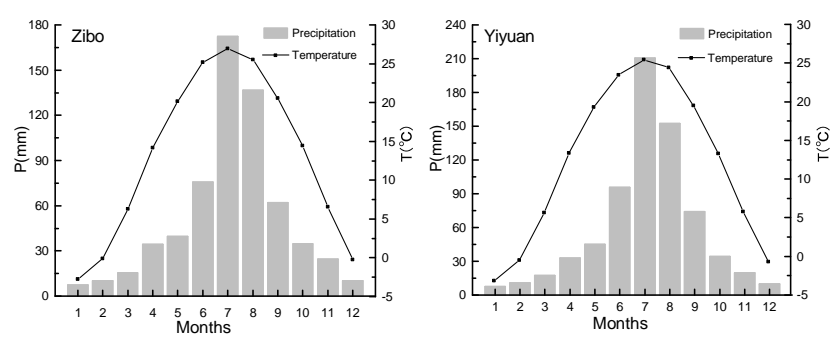

Figure 3. Monthly mean temperature $(T)$ and precipitation $(P)$ of Zibo (1952-1980) at Zibo Station and Yiyuan (1958-2005) at the Yiyuan Station, two meteorological stations close to the study site (Fig. 1).

\section{Analytical methods and data processing}

\subsection{Establishment of a timescale}

The stalagmite ky 1 is conical in shape and consists of very pure calcite (Fig. 4). The polished surface of the stalagmite and observation of the laminae by microscope show that stalagmite ky1 has no hiatus during the growing process. The upper part $(0-42.769 \mathrm{~mm})$ comprises 678 laminae overlain by continuous deposits. All laminae are typical transmitting annual laminae. The stalagmite ky1 has ${ }^{232} \mathrm{Th}$ concentrations ranging from $704.6 \pm 5.1$ to $1245.2 \pm 5.0 \mathrm{ppt}$ (Table 1), which was determined at the High-precision Mass Spectrometry and Environment Change Laboratory (HISPEC) of the National Taiwan University using high-precision dating with the U- ${ }^{230}$ Th technique (Shen et al., 2002).

Because the stalagmite ky1 has no hiatus, the upper part $(0-42.769 \mathrm{~mm})$ contains 678 clear and continuous laminae. These continuous and ongoing laminae have clear and definite chronology meaning themselves. Therefore, based on high-precision dating with the $\mathrm{U}^{230} \mathrm{Th}$ technique, we used the method of counting annual laminae to decide the sedimentation time of each of the laminae and the whole stalagmite ky1 layer by layer and established the timescale of the stalagmite. In the upper part $(0-42.769 \mathrm{~mm})$ of stalagmite ky1, we counted along the upward and downward directions according to some laminae that had high-precision dating results with the U- ${ }^{230} \mathrm{Th}$ technique, confirming times of formation of the 1st and 678th laminae first and then ensuring the age of each of the laminae according to their positions.

\subsection{Measurement of the thickness of the laminae}

The stalagmite ky1 was first cut along the growth axis, and a slice was selected from the profile of the stalagmite and then polished. Second, under the LEIKA DMRX microscope (magnification of $200 \times$, eyepiece of $10 \times$, objective of $20 \times$ ), we used transmission light to observe characteristics of the laminae along the growth axis layer by layer. Third, we measured the thickness of 678 laminae along three different paths layer by layer, calculating the thickness of every one of the 
Table 1. U-series isotopic results and ages for stalagmite ky1 from Kaiyuan Cave-Shandong Peninsula-northern China.

\begin{tabular}{|c|c|c|c|}
\hline Sample ID & 1 & 2 & 3 \\
\hline Dist. from top (mm) & 6.0 & 15.0 & 25.0 \\
\hline${ }^{238} \mathrm{Uppb}^{\mathrm{a}}$ & $347.47 \pm 0.63$ & $434.45 \pm 0.92$ & $334.58 \pm 0.61$ \\
\hline${ }^{232} \mathrm{Th}$ ppt & $1245.2 \pm 5.0$ & $959.9 \pm 4.9$ & $704.6 \pm 5.1$ \\
\hline$\delta^{234}$ Unmeasured & $1457.9 \pm 5.5$ & $1341.2 \pm 5.1$ & $1320.3 \pm 4.6$ \\
\hline$\left[{ }^{230} \mathrm{Th} /{ }^{238} \mathrm{U}\right]$ activity $\mathrm{c}$ & $0.00652 \pm 0.00014$ & $0.00732 \pm 0.00011$ & $0.01021 \pm 0.00013$ \\
\hline$\left[{ }^{230} \mathrm{Th} /{ }^{232} \mathrm{Th}\right] \mathrm{ppm}^{\mathrm{d}}$ & $30.0 \pm 0.68$ & $54.63 \pm 0.89$ & $79.9 \pm 1.2$ \\
\hline Age-uncorrected $\mathrm{BP}^{\mathrm{f}}$ & $289.6 \pm 6.5$ & $341.4 \pm 5.4$ & $480.6 \pm 6.3$ \\
\hline Age-corrected ${ }^{\mathrm{c}, \mathrm{e}} \mathrm{BP}^{\mathrm{f}}$ & $251.1 \pm 20.3$ & $316.4 \pm 13.6$ & $456.6 \pm 13.6$ \\
\hline Age-corrected ${ }^{\mathrm{c}, \mathrm{e}} \mathrm{AD}$ & $1761.9 \pm 20.3$ & $1696.6 \pm 13.6$ & $1556.4 \pm 13.6$ \\
\hline$\delta^{234} \mathrm{U}_{\text {initial }}$ corrected ${ }^{\mathrm{b}}$ & $1458.9 \pm 5.5$ & $1342.4 \pm 5.1$ & $1322.1 \pm 4.6$ \\
\hline
\end{tabular}

Chemistry was performed on 8 July 2013 with the analysis method of Shen et al., 2003), and instrumental analysis on MC-ICP-MS (Shen et al., 2012). Analytical errors are $2 \sigma$ of the mean. ${ }^{a}\left[{ }^{238} \mathrm{U}\right]=\left[{ }^{235} \mathrm{U}\right] \times 137.818( \pm 0.65 \%$ ) (Hiess et al., 2012); $\delta^{234} \mathrm{U}=\left(\left[{ }^{234} \mathrm{U} /{ }^{238} \mathrm{U}\right]\right.$ activity -1$) \times 1000 .{ }^{\mathrm{b}} \delta^{234} \mathrm{U}_{\text {initial }}$ corrected was calculated based on ${ }^{230} \mathrm{Th}$ age $(T)$, i.e., $\delta^{234} \mathrm{U}_{\text {initial }}=\delta^{234} \mathrm{U}_{\text {measured }} \times e^{\lambda 234 \times T}$, and $T$ is the corrected age.

${ }^{\mathrm{c}}\left[{ }^{230} \mathrm{Th} /{ }^{238} \mathrm{U}\right]_{\text {activity }}=1-e^{-\lambda 230 T}+\left(\delta^{234} \mathrm{U}_{\text {measured }} / 1000\right)\left[\lambda_{230} /\left(\lambda_{230}-\lambda_{234}\right)\right]\left(1-e^{-(\lambda 230-\lambda 234)^{T}}\right)$, where $T$ is the age. Decay constants are $9.1705 \times 10^{-6}$ for ${ }^{230} \mathrm{Th}, 2.8221 \times 10^{-6}$ for ${ }^{234} \mathrm{U}$ (Cheng et al., 2013, EPSL), and $1.55125 \times 10^{-10} \mathrm{yr}^{-1}$ for ${ }^{238} \mathrm{U}$ (Jaffey et al., 1971). ${ }^{\mathrm{d}}$ The degree of detrital ${ }^{230} \mathrm{Th}$ contamination is indicated by the $\left[{ }^{230} \mathrm{Th} /{ }^{232} \mathrm{Th}\right]$ atomic ratio instead of the activity ratio. ${ }^{\mathrm{e}}$ Age corrections for samples were calculated using an estimated atomic ${ }^{230} \mathrm{Th} /{ }^{232} \mathrm{Th}$ ratio of $4 \pm 2 \mathrm{ppm}$. Those are the values for a material at secular equilibrium, with the crustal ${ }^{232} \mathrm{Th} /{ }^{238} \mathrm{U}$ value of 3.8 . The errors are arbitrarily assumed to be $50 \%$. ${ }^{\mathrm{f}} \mathrm{BP}$ (Before Present), "present" in this table refers to $\mathrm{AD} 2013$.

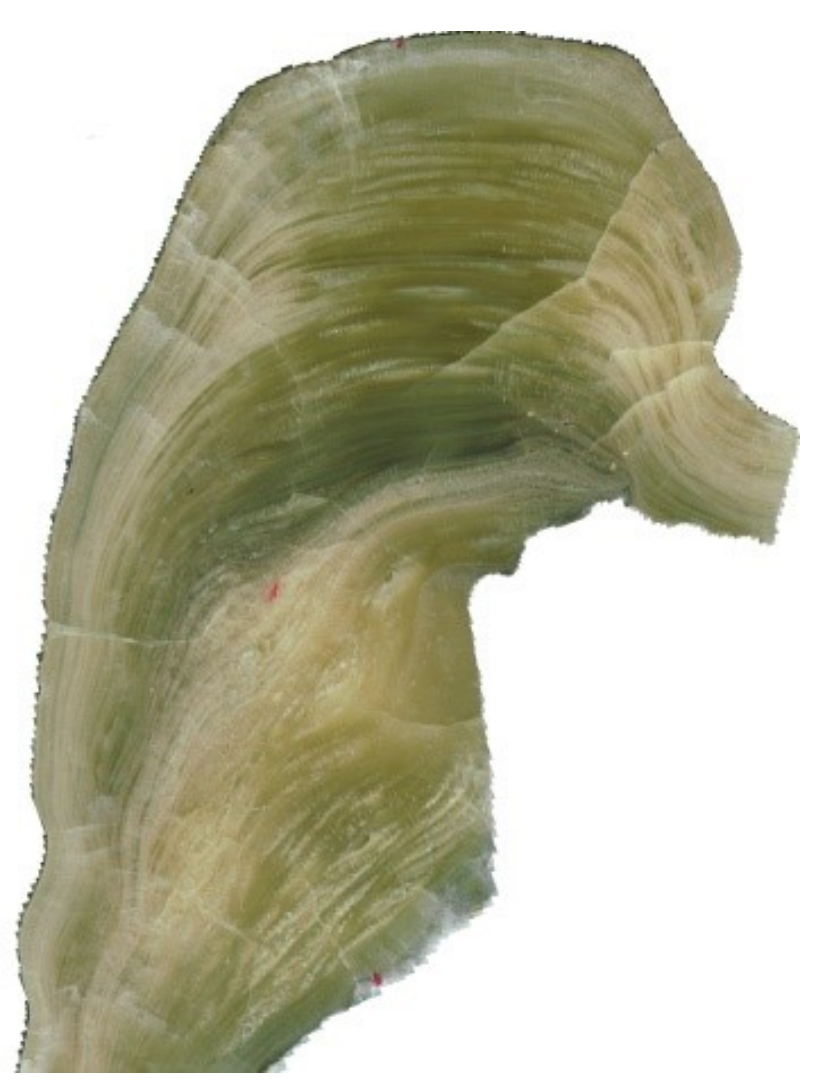

Figure 4. Polished longitudinal cross section of stalagmite ky1.

laminae on average according to the three data points for each of the laminae. Fourth, we dated every one of the lam- inae layer by layer and determined the time series data for the thickness of the laminae of the stalagmite. Finally, we contrasted the time series data and the $\delta^{18} \mathrm{O}$ ratio data series, analyzed the paleoclimate environment characteristic of the different stages and discussed the climatic-environmental meaning of the variations in the thickness of the laminae.

\section{$3.3 \delta^{18} \mathrm{O}$ isotope test}

First, perpendicular to the growth axis and along the position of 9.5 and $18.5 \mathrm{~mm}$ from the top, we collected four samples equally spaced at $20 \mathrm{~mm}$ from the growth center that were used for the Hendy test. Second, along the direction of growth, we collected a $4 \mathrm{~mm}$ depth $\times 5 \mathrm{~mm}$ width $\times 75 \mathrm{~mm}$ length stone strip along growing axis, and scraped 330 samples using medical scalpel from top to bottom with a sampling density of 7-8 samples/mm (separation distance of $0.1296 \mathrm{~mm}$ on the average). From the 330 samples, we chose 175 samples to measure their $\delta^{18} \mathrm{O}$ ratios, basically following the principle of an interval test to avoid the mixed pollution between adjacent samples. Next, we confirmed the sedimentation time according to their positions and formed the time series data for $\delta^{18} \mathrm{O}$ ratios. The $\delta^{18} \mathrm{O}$ ratios were measured using an automated individual carbonate reaction (Kiel) device coupled with a Thermo-Fisher MAT 253 mass spectrometer at the State Key Laboratory of Palaeobiology and Stratigraphy of the Nanjing Institute of Geology and Palaeontology, Chinese Academy of Sciences. Each powdered sample ( $\sim 0.08$ to $0.1 \mathrm{mg}$ of carbonate) was reacted with $103 \% \mathrm{H}_{3} \mathrm{PO}_{4}$ at $90{ }^{\circ} \mathrm{C}$ to liberate sufficient $\mathrm{CO}_{2}$ for isotopic analysis. The standard used is NBS-19, and one stan- 
dard was analyzed with every 10 samples. One sample out of 10 was duplicated to check the replication. All isotope ratios are reported in per mil (\%o) deviations relative to the Vienna Peedee Belemnite (VPDB) standard in the conventional manner. The standard deviation $(1 \sigma)$ for replicate measurements on NBS-19 is $\leq 0.10 \%$.

\section{Results and discussion}

\subsection{The thickness of the stalagmite laminae and the results of dating}

In the upper part $(0-42.769 \mathrm{~mm})$ of stalagmite ky1, the dating results for ages corrected in Table 1 show that the three samples in the positions of 6,15 and $25 \mathrm{~mm}$ are dated at AD $1761.9 \pm 20.3,1696.6 \pm 13.6$ and $1556.4 \pm 13.6$ respectively (Table 1). Altogether, there are 221 laminae between the positions of 6 and $25 \mathrm{~mm}$, and their age intervals are 206 years according to the $\mathrm{U}^{230} \mathrm{Th}$ dating results. The difference in age between the laminae determined by counting and by $\mathrm{U}^{230} \mathrm{Th}$ dating is only 15 years. However, there are 109 laminae between the positions of 6 and $15 \mathrm{~mm}$, and their age intervals are 65 years according to the result of the $\mathrm{U}^{230} \mathrm{Th}$ dating. There are 112 laminae between the positions of 15 and $25 \mathrm{~mm}$, and their age intervals are 141 years according to the results of $\mathrm{U}-^{230} \mathrm{Th}$ dating. If we use the position of $6 \mathrm{~mm}$ as a datum for calculation, the ages of the $1 \mathrm{st}$ and 678th laminae are $\mathrm{AD} 1894 \pm 20.3$ and $1217 \pm 20.3$ respectively. If we use the position of $25 \mathrm{~mm}$ as a datum for calculation, the ages of the 1st and 678th laminae are AD $1909 \pm 13.6$ and AD $1232 \pm 13.6$ respectively. The age intervals are only different by 14 years. Finally, considering the error of the measurement of the thickness of the laminae accumulating downward layer by layer, we chose the 133rd of the laminae corresponding to the position of $6 \mathrm{~mm}$ as a datum to calculate the age of the other laminae in the upper part of stalagmite ky1. The results show that the deposition times of the 1st and 678th laminae are AD $1894 \pm 20.3$ and $1217 \pm 20.3$ (the dating error is \pm 20.3 years, similar hereafter for the AD ages in this paper), respectively; the ages of the other laminae were calculated by analogy. Thus, we obtained the time series data for the thickness of the laminae of stalagmite ky1 (Fig. 5).

\subsection{Characteristics of the shape of the laminae}

Stalagmite ky1 obviously developed continuous transmitting laminae (Fig. 4). Under the microscope, first, the thickness of the laminae is rather changeable. The maximum thickness is more than $800 \mu \mathrm{m}$, and the minimum thickness is less than $15 \mu \mathrm{m}$ (Fig. 6a). Because the variations in the thickness of the laminae may correspond to the climatic environmental changes when the laminae were growing, the potential value of these transmitting laminae for reconstructing the paleoclimate environment is illustrated (Genty et al., 1996; Baker et al., 1999; Tan et al., 2004; Ban et al., 2005; Y. H. Liu et al.,

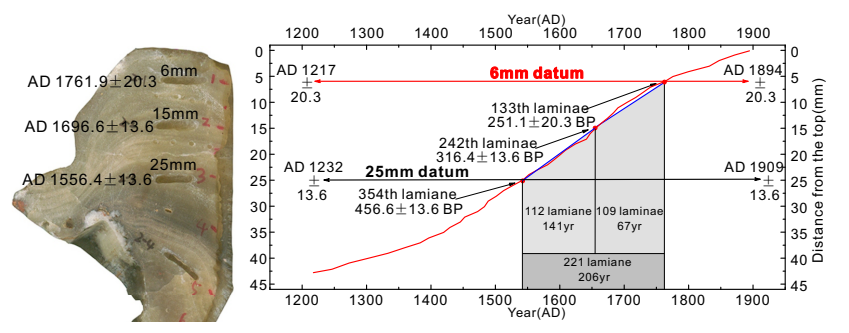

Figure 5. The age model for stalagmite ky1 established by counting of laminae and high-precision dating results with the $\mathrm{U}-{ }^{230} \mathrm{Th}$ technique. This figure is the photo of stalagmite ky1, and the age label was based on high-precision dating results with the $\mathrm{U}-{ }^{230} \mathrm{Th}$ technique on the left. The blue line is the high-precision dating results with the U- ${ }^{230}$ Th technique and the connecting lines. The red line is the age scale established by this article. The ages of other laminae were determined by annual laminae counting upward and downward based on the 133rd of the laminae corresponding to the position of $6 \mathrm{~mm}$. The date of which is AD $1762 \pm 20.3$ decided by high-precision dating results with the $\mathrm{U}^{230} \mathrm{Th}$ technique.

2005; Zhang et al., 2008; Muangsong et al., 2014; D. B. Liu et al., 2015). Second, most of the boundaries of the laminae are straight, but some laminae are obviously curved (Fig. 6b). When we analyzed the climatic-environmental meaning of the thickness of the stalagmite laminae, we acquired the laminae thickness values of the same laminae in different paths and calculated their average values along multiple paths to determine the substituted index information for climaticenvironmental change that had statistical significance. Third, colors in some of the boundaries of the transmitting laminae are obviously deeper (Fig. 6c). These laminae have a special structure similar to supra-annual laminae. This special structure may indicate that climatic-environmental changes not only have seasonal changes but also have multi-interannual changes. Fourth, the light transmission of some transmitting laminae is obviously different from the light transmission of adjacent laminae: the color is deeper, and there are dark spots (Fig. 6a, d). Whether these dark laminae have some mineralogy and geochemistry characteristics different from other transmitting laminae and what their climatic-environmental significance may be, these dark laminae may need further and special research in the future.

\subsection{Variations in the thickness of the laminae}

The range of variation in the thickness of the 678 laminae of stalagmite ky1 (upper part) is $13.03-872.8 \mu \mathrm{m}$. The age determined for the maximum thickness $(872.8 \mu \mathrm{m})$ of the laminae is $\mathrm{AD} 1551$. The age determined for the minimum thickness $(13.03 \mu \mathrm{m})$ of the laminae is $\mathrm{AD} 1245$ and the average value for all laminae is $63.08 \mu \mathrm{m}$ (Fig. 7a). In the 678 years from AD 1217 to 1894, the thickness of the laminae from stalagmite ky1 have obvious stages of variation. Stalagmite ky1 had undergone the transition from low values to high values 

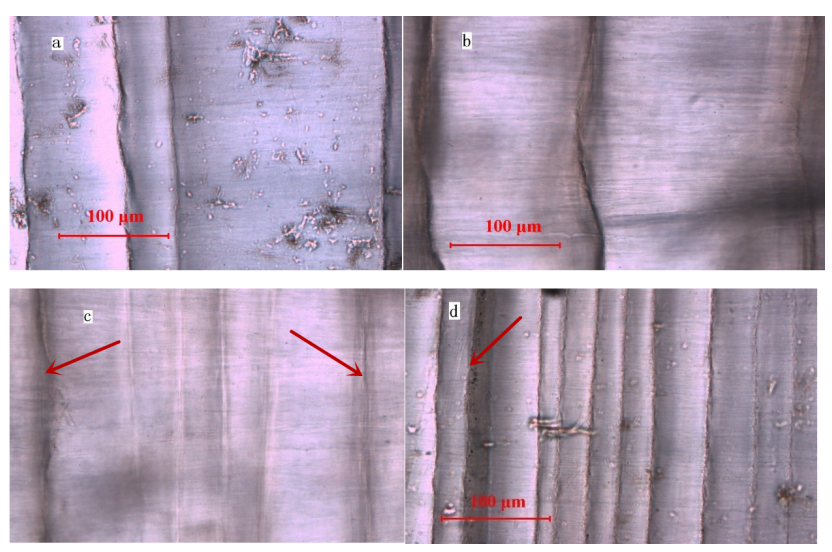

Figure 6. The characteristics of the transmitting laminae in the upper part of stalagmite ky 1 show that the thickness of the laminae has obvious variations. The boundary was curved, and the color near the boundary was deeper because of the dark transmitting laminae. The thickness of the laminae shows obvious variations (a), the curve of the boundary of transmitting laminae (b), the color variations of the boundary of transmitting laminae, the arrows indicating the darker boundaries, the boundaries in the middle were obviously whiter (c), dark transmitting laminae (d) (the arrows indicated in the figure).

and again to low values, and both the thickness of the laminae and the fluctuating degree of variation in the thickness of the laminae had obvious stages of variation (Fig. 7a). AD 12171471 was the low-value period of thickness of the laminae with an average value of $46.08 \mu \mathrm{m}$. Then, the period from $\mathrm{AD} 1217$ to 1372 was a relatively low-fluctuation period. The period from $\mathrm{AD} 1372$ to 1471 was a period of relatively high fluctuation. The two periods above presented the trend of rising first and then falling. AD 1471-1744 was a period of high value and high fluctuation in the thickness of the laminae, with the average value of $88.8307 \mu \mathrm{m}$. This period could be divided into three secondary high-value-high-fluctuation periods: AD 1471-1548, 1548-1637 and 1637-1744. Every period shows the trend of increasing first and then decreasing. The average values for the thickness of the laminae were $82.2027,82.5491$ and $98.8252 \mu \mathrm{m}$, successively. From AD 1744 to 1894, there was a period of relatively low values of the thickness of the laminae, with a group of peak values appearing in approximately AD 1776 with an average value of $45.1164 \mu \mathrm{m}$. The period from AD 1217 to 1372 was a period of relatively low fluctuation. The period from AD 1744 to 1831 was a period of relatively high fluctuation. The two periods above present the trend of rising first and then falling. The period from AD 1831 to 1880 was a period of relatively high fluctuation, without a trend of obviously rising or falling. The period of rising was short from AD 1880 to 1894 .
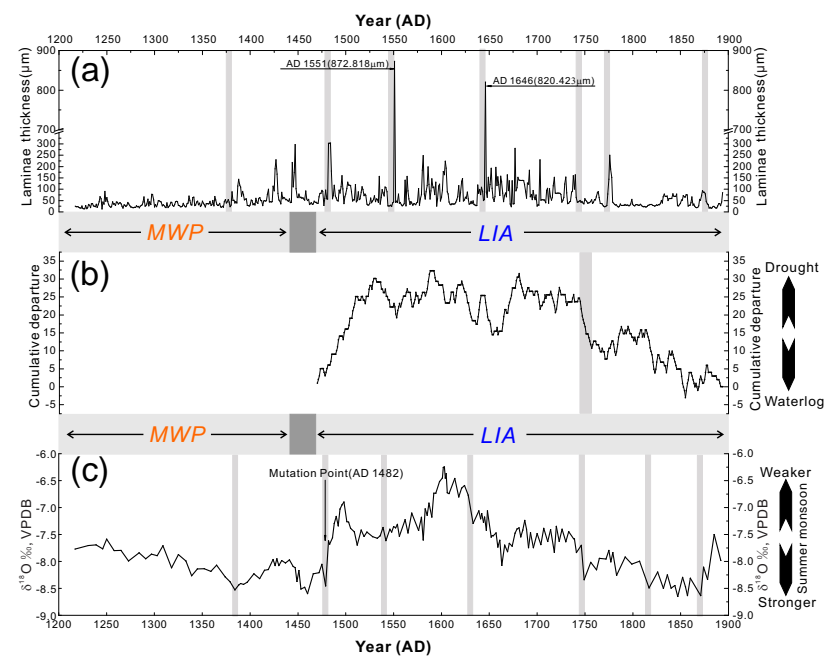

Figure 7. The year of formation and the thickness data series of the 678 laminae in the upper part (0-42.769 mm) of stalagmite ky1 (a), the cumulative departure curve (b) and the $\delta^{18} \mathrm{O}$ ratio data series for 172 samples (c). The thicknesses of the laminae formed in AD 1551 and 1646 were up to 872.818 and $820.423 \mu \mathrm{m}$, respectively, much higher than other laminae. The cumulative departure curve (b) is drawn by drought-waterlog indices on the basis of the Yearly Charts of Dryness/Wetness in China for the Last 500-Year Period (Chinese Academy of Meteorological Sciences of the China Meteorological Administration, 1981). The curve has a rising trend representing less precipitation and the climate becoming drier, and the curve has a declining trend representing more precipitation and the climate becoming waterlogged.

\subsection{Variations in the $\delta^{18} \mathrm{O}$ ratio}

The variation range of $\delta^{18} \mathrm{O}$ ratios in the 172 samples above is -6.247 to $-8.599 \%$, with the maximum value $(-6.247 \%$ ) appearing in $\mathrm{AD} 1603$ and the minimum value $(-8.599 \%$ ) appearing in AD 1460. The value of all of the samples is $-7.674 \%$ on average (Fig. 7c). In the 678 years from $\mathrm{AD} 1217$ to $1894, \delta^{18} \mathrm{O}$ ratios had obvious stages of variation. The ratios had undergone a transition from low values to high values and again to low values, and both the $\delta^{18} \mathrm{O}$ ratios and the degree of fluctuation of $\delta^{18} \mathrm{O}$ ratios had obvious stages of variation (Fig. 7c). From AD 1217 to 1480 , there was a period of low values of $\delta^{18} \mathrm{O}$ ratios with an average value of $-8.104 \%$. The period from AD 1217 to 1384 was a period of relatively low fluctuation. This period had a trend of decreasing slowly. The period from AD 1384 to 1480 was a period of relatively high fluctuation, and this period showed the trend of rising first and then falling. AD 1480-1746 was a period of high value and high fluctuation with an average value of $-7.301 \%$. This period could be divided into three secondary high-value-highfluctuation periods: AD 1480-1542, 1542-1633 and 16331746. Every secondary period had the trend of increasing first and then decreasing or decreasing first and then increasing. The inflection points appeared in the ages of AD 1498, 
1603 and 1663 , respectively. The average values of the $\delta^{18} \mathrm{O}$ ratios were $-7.393,-6.953$ and $-7.513 \%$, successively. AD 1764-1894 was a low-value period with an average value of $-8.199 \%$. The period from AD 1746 to 1831 was a period of relatively high fluctuation. This period showed a trend of rising first and then falling. The period from AD 1831 to 1880 was a period of relatively low fluctuation and did not have a trend of obviously rising or falling. There was a short rising period from $\mathrm{AD} 1880$ to 1894.

\subsection{Drought-waterlog index variations}

To show the relationship between the variations in the thickness of the laminae, the $\delta^{18} \mathrm{O}$ ratios and the changes in climate, we calculated cumulative departure values for the drought-waterlog index in the area of Kaiyuan Cave from AD 1470 to 1894 . The data source was the Yearly Charts of Dryness/Wetness in China for the Last 500-year Period. The charts are compiled by the Chinese Academy of Meteorological Sciences of the China Meteorological Administration according to extensive Chinese historical literature and published by the China Cartographic Publishing House (Chinese Academy of Meteorological Sciences of the China Meteorological Administration, 1981). In the charts, the degree of drought-waterlog is represented by the drought-waterlog index, which has five values including 1,2,3, 4 and 5 - with 1 representing the waterlog and 5 representing drought - and its distribution is represented through the index isolines. On the basis of Yearly Charts of Dryness/Wetness in China for the Last 500-Year Period, we acquired the drought-waterlog indices for the area near Kaiyuan Cave according to its geographical coordinates, and we checked the drought-waterlog indices again referring to the local chronicles. We drew a cumulative departure curve from AD 1470 to 1894 with a rising trend representing the changes associated with becoming dryer and a declining trend representing the change associated with becoming waterlogged (Fig. 7b). Based on the cumulative departure curve, there was a period of less precipitation in this area from AD 1480 to 1744 . This period started with the transition of MWP/LIA and ends with the transition of LIA/CWP. The primary fluctuations of this period correspond to the curve of the thickness of the laminae. (Fig. 7b). The high-value-high-fluctuation period of the thickness of stalagmite ky1 laminae above occurred under the background of drought and less precipitation. However, there is a correlation between the $\delta^{18} \mathrm{O}$ ratios of stalagmite ky1 and the change in the summer monsoon intensity and precipitation (Cheng et al., 2009). So, there is a correlation between the summer monsoon intensity and precipitation and the growth of stalagmites: the weaker summer monsoon intensity together with less precipitation may be of benefit to the growth of stalagmites during LIA.
Table 2. The results of the Hendy tests conducted along two growth laminae of ky1 at depths of 9.5 and $18.5 \mathrm{~mm}$ individually, which indicate that calcite in ky1 was deposited under isotopic equilibrium conditions according to the Hendy test rules (Hendy, 1971).

\begin{tabular}{lccc}
\hline & $\begin{array}{c}\text { Distance from } \\
\text { the top } \\
\mathrm{mm}\end{array}$ & $\begin{array}{c}\text { Distance from the } \\
\text { Center of growth } \\
\mathrm{mm}\end{array}$ & $\delta^{18} \mathrm{O} / \% 0$ \\
\hline KY1-9/10-5 & & 5.0 & -7.506 \\
KY1-9/10-10 & 9.5 & 10.0 & -7.753 \\
KY1-9/10-15 & & 15.0 & -7.981 \\
KY1-9/10-20 & & 20.0 & -7.691 \\
\hline KY1-18/19-5 & & 5.0 & -6.571 \\
KY1-18/19-10 & 18.5 & 10.0 & -6.671 \\
KY1-18/19-15 & & 15.0 & -6.540 \\
KY1-18/19-20 & & 20.0 & -6.542 \\
\hline
\end{tabular}

\subsection{Climatic-environmental meanings of variations in the thickness of the laminae}

Because the difference in homologous thickness stages of the laminae and $\delta^{18} \mathrm{O}$ ratios ranges from 2 years to 14 years, the error of the dating technique is \pm 20 years (the time series data from Sect. 4.1), and the resolution of the $\delta^{18} \mathrm{O}$ sample is 3.9 years, we may conclude that the two synchronize with time variation; i.e., the low-value period and the high-value period of the $\delta^{18} \mathrm{O}$ ratios correspond to the low-value period and the high-value period of the thickness of the stalagmite laminae. The low-fluctuation period and the high-fluctuation period for the $\delta^{18} \mathrm{O}$ ratios correspond to the low-fluctuation period and high-fluctuation period of thickness of stalagmite laminae (Fig. 7a, c). The analysis result for the $\delta^{18} \mathrm{O}$ variations shows that $\delta^{18} \mathrm{O}$ ratios for the four samples are -7.506 , $-7.753,-7.981$ and $-7.691 \%$ for the samples that are collected at a $9.5 \mathrm{~mm}$ distance from the top of the stalagmite and the 5,10, 15 and $20 \mathrm{~mm}$ distance from the axis of growth, respectively. The $\delta^{18} \mathrm{O}$ ratios for the four samples that are collected at an $18.5 \mathrm{~mm}$ distance from the top of the stalagmite are $-6.571,-6.671,-6.540$ and $-6.542 \%$. At $5,10,15$ and $20 \mathrm{~mm}$ distances from the axis of growth, respectively, and the $\delta^{18} \mathrm{O}$ ratios are similar for the same laminae (Table 2). Hence, the Hendy test carried out for ky1 indicates that calcite in ky1 should be deposited under isotopic equilibrium conditions. The possibility of the dynamic fractionation of the calcite in the sedimentary process is small; therefore, the stalagmite $\delta^{18} \mathrm{O}$ mainly reflects the original external climate signal (Hendy, 1971). Therefore, the stalagmite $\delta^{18} \mathrm{O}$ can be used to collect and reconstruct the information on climate change (Tan et al., 2009, 2013; Kuo et al., 2011; Li et al., 2011; Liu et al., 2015).

The obvious synchronization relationship between the variations in the thickness of the laminae and the $\delta^{18} \mathrm{O}$ ratios variations in stalagmite ky1 shows a close relationship between the variations in the deposition rate of the stalag- 
mite and climate change (Fig. 7). Because Kaiyuan Cave is located in a warm temperate zone influenced by the East Asia monsoon, its rainy season coincides with high temperatures. The precipitation, carried by the summer monsoon from the low latitudes of the Pacific Ocean, is concentrated in summer. However, when the winter monsoon from the interior Asian continent at a high latitude prevails, rarely is there precipitation. In this research, we interpreted the climatic meanings of the stalagmite ky $1 \delta^{18} \mathrm{O}$ ratios, based on the relationship between the cumulative departure of the droughtwaterlog index and the curves of the $\delta^{18} \mathrm{O}$ ratios. In consideration of characteristics of contemporary warm temperate weather, also referring to the assumption of the Asia monsoon intensity by Cheng et al. (2009) and the precipitation assumed by Zhang et al. (2008) about the climatic meanings of stalagmite $\delta^{18} \mathrm{O}$ records, with lower $\delta^{18} \mathrm{O}$ ratios representing a stronger summer monsoon and higher $\delta^{18} \mathrm{O}$ ratios representing a weaker summer monsoon, the $\delta^{18} \mathrm{O}$ ratios are anti-correlative with precipitation (Fig. 7). There was a strong summer monsoon and more-precipitation period from AD 1217 to 1480, a weak summer monsoon and less-precipitation period from AD 1480 to 1746 and a strong summer monsoon and more-precipitation period again from AD 1746 to 1894. The degree of fluctuation of the summer monsoon intensity and precipitation is not the same or similar in different periods. As a whole, the degree of fluctuation was lower when the summer monsoon was stronger and the precipitation was more. The degree of fluctuation was higher when the summer monsoon was weaker and the precipitation was less. The period from AD 1217 to 1480 can be divided into one low-fluctuation period and one high-fluctuation period. The period from AD 1480 to 1746 can be divided into three high-fluctuation periods. The period from AD 1746 to 1894 included a high-fluctuation period, a low-fluctuation period and a weaker and less fluctuation period, successively.

According to the thickness of the laminae and the $\delta^{18} \mathrm{O}$ record of stalagmite ky1, the thickness of the laminae and both summer monsoon intensity and precipitation have a negative correlation. The higher-value period of the thickness of the laminae corresponds to weaker summer monsoon and less precipitation, and the lower value corresponds to stronger summer monsoon and more precipitation. The thickness of the laminae and the degree of fluctuation of the summer monsoon intensity and precipitation have a positive correlation. The period of the higher values for the thickness of the laminae corresponds to a high degree of fluctuation of the summer monsoon intensity and precipitation, and a lower value corresponds to a low degree of fluctuation in the summer monsoon and precipitation. Therefore, Kaiyuan Cave, in the coastal area both of a warm temperate zone and the East Asia monsoon area, demonstrates that the variations in the thickness of the laminae are not only relative to the summer monsoon intensity and precipitation but also relative to their degree of fluctuation. This is because karstic water cycles faster and residence time is shorter in the fracture of rock. The dissolution was insufficient and weak; therefore, the deposition rate and the thickness of the laminae from the stalagmite were low in the period with more precipitation. However, in the period of less precipitation, the karstic water cycled slower, the residence time was longer in the fracture of the rock, and the dissolution was sufficient and strong; therefore, the deposition rate and the thickness of the laminae of the stalagmite were high. However, karstic water would be reduced or dry up if the period of less precipitation lasted for a long time. The period of less precipitation is also bad for water dissolution and growth of the stalagmite laminae. Under the background of weaker summer monsoons and less precipitation, the degree of fluctuation of the summer monsoon intensity and precipitation becomes higher, beneficial to increasing the average value of the thickness of the laminae of the stalagmite, but the degree of fluctuation also becomes higher. Because of the degree of fluctuation of the summer monsoon intensity and precipitation reflecting the degree of climatic stabilization, according to both the thickness of the laminae and the $\delta^{18} \mathrm{O}$ record of stalagmite ky1 from the Kaiyuan Cave, the climate change between MWP and LIA in the coastal area of both a warm temperate zone and the East Asia monsoon area, in addition to less precipitation and a lower temperature, also shows that the degree of climatic stability obviously decreased.

\section{Conclusions}

The upper part of stalagmite ky1 $(0-42.769 \mathrm{~mm})$ clearly consists of 678 continuously transmitting annual laminae. The time of deposition ranges from $\mathrm{AD} 1217 \pm 20$ to $1894 \pm 20$; therefore, the laminae contain the climatic-environmental change information for the late MWP, the whole LIA and the early CWP. The analysis shows that both the variations in the thickness of the laminae themselves and the fluctuating degree of variation in the thickness of the laminae of stalagmite ky1 have obviously staged characteristics from AD 1217 to 1894. Both the variations in the thickness of the laminae themselves and the fluctuating degree of variation in the thickness of the laminae of stalagmite ky1 had undergone the transition from low values to high values and again to low values, synchronized with the contemporaneous variations in the $\delta^{18} \mathrm{O}$ ratios and the degree of fluctuation of the $\delta^{18} \mathrm{O}$ ratios. According to the comparison among the thicknesses of the laminae, the drought-waterlog index and the synchronous $\delta^{18} \mathrm{O}$ ratios of stalagmite ky1, the thickness of the laminae and the summer monsoon intensity and precipitation have a negative correlation. The higher-value periods of the thickness of the laminae correspond to weaker summer monsoon and less precipitation, and low-value periods correspond to stronger summer monsoon and more precipitation. The thickness of the laminae and the degree of fluctuation of the summer monsoon intensity and precipitation have a positive correlation. The higher-value periods of thickness of the 
laminae correspond to a high degree of fluctuation of summer monsoon intensity and precipitation, and the lower-value periods correspond to a low degree of fluctuation in the summer monsoon and precipitation. Therefore, Kaiyuan Cave, in the coastal area both of a warm temperate zone and the East Asia monsoon area, with the relationship between the variations in thickness of the laminae and climate change, in addition to the effects of climate factor variations such as temperature and precipitation on the thickness of the laminae, also reflects closely the degree of fluctuation of the summer monsoon intensity and the degree of climatic stability. On the whole, there was a period of stronger summer monsoons from AD 1217 to 1470 . The climatic stability was high from AD 1217 to 1370 first and was reduced from AD 1370 to 1470 . From AD 1470 to 1740 , there was a period of weaker summer monsoon and lower degree of stability that could be divided into three secondary periods with a trend of stronger first and then weaker or weaker first and then stronger divided by AD 1550 and 1640. Since AD 1640, the summer monsoon has again entered a strong period. The degree of stability was high from AD 1740 to 1830, and the degree of stability was reduced from AD 1830 to 1880 . The summer monsoon became weaker for a short time since AD 1880.

The conclusions of this research can enrich the knowledge about the climatic-environmental meaning of the thickness of the laminae of a stalagmite, contribute to the comprehension of the specific manifestation of the MWP and LIA in the coastal area both of a warm temperate zone and the East Asia monsoon area of northern China, especially the transition time of MWP/LIA and the lasting time and the climatic characteristics of the LIA, and deepen the research into the climate change in the Asian summer monsoon area based on the secondary carbonate record in the karst cave.

Acknowledgements. This research was funded by the National Natural Science Foundation of China (NNSFC, no. 41171158). U-Th dating was finished in the High-precision Mass Spectrometry and Environment Change Lab (HISPEC) with partial support of MOST (104-2119-M-002-003 to C.-C. Shen) and the National Taiwan University (105R7625 to C.-C. Shen). The authors thank Jiang Xiuyang (Fujian Normal University) for his help in sample collection and high-precision dating with the U-Th techniques.

Edited by: D. Fleitmann

\section{References}

Baker, A., Smart, P. L, and Edwards, R. L.: Annual growth banding in a cave stalagmite, Nature, 364, 518-520, 1993.

Baker, A., Proetor, C. J., and Barnes, W. L.: Variations in stalagmite luminescence laminae structure at Pool's Cave, England, AD 1910-1996: Calibration of a palaeo precipitation proxy, The Holocene, 9, 683-688, 1999.
Baldini, J. U. L.: Cave atmosphere controls on stalagmite growth rate and palaeoclimate records. Geological Society, London, Special Publications, 336, 283-294, 2010.

Baldini, J. U. L., McDermott, F., Baker, A., Baldini, L. M., Mattey, D. P., and Railsback, L. B.: Biomass effects on stalagmite growth and isotope ratios: A 20th century analogue from Wiltshire, England, Earth Planet. Sci. Lett., 240, 486-494, 2005.

Ban, F. M., Pan, G. X., and Wang, X. Z.: Timing and possible mechanism of organic substances formation in stalagmites liminae from Beijing Shihua Cave, Quaternary Sci., 25, 265-268, 2005 (in Chinese with English Abstract).

Brook, G. A., Rafter, M. A., Railsback, L. B., Sheen, S. W., and Lundberg, J.: A high resolution proxy record of rainfall and ENSO since AD 1550 from layering in stalagmites from Anjohibe cave, Madagascar, The Holocene, 9, 695-705, 1999.

Burns, S. J., Fleitmann, D., Matter, A., Kramers, J., and Al-Subbary, A. A.: Indian Ocean Climate and an Absolute Chronology over Dansgaard/Oeschger Events 9 to 13, Science, 301, 1365-1367, 2003.

Cai, B., Zhu, J., Ban, F., and Tan, M.: Intra-annual variation of the calcitede position rate of drip water in Shihua Cave, Beijing, China and its mplications for palaeoclimatic reconstructions, Boreas, 40, 525-535, 2011.

Cheng, H., Edwards, R. L., Broecker, W. S., Denton, G. H., Kong, X. G., Wang, Y.-J., Zhang, R., and Wang, X. F.: Ice age terminations, Science, 236, 248-252, 2009.

Cheng, H., Edwards, R. L., Shen, C. C., Polyak, V. J., Asmerom, Y., Woodhead, J., Hellstrom, J., Wang, Y. J., Kong, X. G., Spötl, C., Wang, X. F., and Alexander Jr., E. C.: Improvements in ${ }^{230} \mathrm{Th}$ dating, ${ }^{230} \mathrm{Th}$ and ${ }^{234} \mathrm{U}$ half-life values, and U-Th isotopic measurements by multi-collector inductively coupled plasma mass spectrometry, Earth Planet. Sci. Lett., 371/372, 82-91, 2013.

Chinese academy of meteorological sciences of China Meteorological Administration: Yearly charts of dryness/wetness in China for the last 500-year period, Beijing, China, China Cartographic Publishing House, 1981 (in Chinese).

Committee on Surface Temperature Reconstructions for the Last 2,000 Years and National Research Council: Surface temperature reconstructions for the last 2000 years, National Academies Press, Washington, DC, 2006.

Duan, W., Cai, B., Tan, M., Liu, H., and Zhang, Y.: The growth mechanism of the aragonitic stalagmite laminae from Yunnan $\mathrm{Xi}$ anren Cave, SW China revealed by cave monitoring, Boreas, 41, 113-123, 2012.

Dykoski, C. A., Edwards, R. L., Cheng, H., Yuan, D. X., Cai, Y. J., Zhang, M. L., Lin, Y. S., Qing, J. M., An, Z. S., and Revenaugh, J.: A high-resolution, absolute-dated Holocene and deglacial Asian monsoon record from Dongge Cave, China, Earth Planet. Sci. Lett., 233, 71-86, 2005.

Fairchild, I. J, Smith, C. L., Baker, A., Fuller, L., Spötl, C., Mattey, D., and McDermott, F.: Modification and preservation of environmental signals in speleothems, Earth-Sci. Rev., 75, 105-153, 2006.

Fleitmann, D., Burns, S.J., Mudelsee, M., Neff, U., Kramers, J., Mangini, A., and Matter, A.: Holocene Forcing of the Indian Monsoon Recorded in a Stalagmite from Southern Oman, Science, 300, 1737-1739, 2003.

Frisia, S., Borsato, A., Preto, N., and McDermott, F.: Late Holocene annual growth in three Alpine stalagmites records the influence 
of solar activity and the North Atlantic Oscillationon winter climate, Earth Planet. Sci. Lett., 216, 411-424, 2003.

Genty, D. and Quinif, Y.: Annually laminated sequences in the internal structure of some Belgian stalagmites importance for paleoclimatology, J. Sediment. Res., 66, 275-288, 1996.

Genty, D., Blamart, D., Ouahdi, R., Gilmour, M., Baker, A., Jouzel, J., and Van-Exter, S.: Precise dating of Dansgaard-Oeschger climate oscillations in Western Europe from stalagmite data, Nature, 421, 833-837, 2003.

Hendy, C. H.: The isotopic geochemistry of speleothems (Part I). The calculation of the effects of different modes of formation on the isotopic composition of speleothems and their applicability as palaeoclimatic indicators, Geochim. Cosmochim. Ac., 35, 801824,1971

Hiess, J., Condon, D. J., McLean, N., and Noble, S. R.: ${ }^{238} \mathrm{U} /{ }^{235} \mathrm{U}$ Systematics in Terrestrial Uranium-Bearing Minerals, Science, 30, 1610-1614, 2012.

Hou, J. Z., Tan, M., Cheng, H., and Liu, T. S.: Stable isotope records of plant cover change and monsoon variation in the past 2200 years: evidence from laminated stalagmites in Beijing, China, Boreas, 32, 304-313, 2003.

Jaffey, A. H. K., Flynn, K. F., Glendenin, L. E., Bentley, W. C., and Essling, A. M.: Precision measurement of half-lives and specific activities of ${ }^{235} \mathrm{U}$ and ${ }^{238} \mathrm{U}$, Phys. Rev. C, 4, 1889-1906, 1971.

Kuo, T. Z., Liu, Z. Q., Li, H. C., Wan, N. J., Shen, C. C., and Ku, T. L.: Climate and environmental changes during the past millennium in central western Guizhou, China as recorded by Stalagmite ZJD-21, J. Asian Earth Sci., 40, 1111-1120, 2011.

Lamp, H. H.: The early medieval warm epoch and its sequel, Palaeogeogr. Palaeoclimatol., 1, 13-37, 1965.

Lamp, H. H.: Climate: present, past and future, Methuen, London, 1972.

Li, H. C., Lee, Z. H., Wan, N. J., Shen, C. C., Li, T. Y., Yuan, D. $\mathrm{X}$., and Chen, Y. H.: The $\delta^{18} \mathrm{O}$ and $\delta^{13} \mathrm{C}$ records in an aragonite stalagmite from Furong Cave, Chongqing, China: A-2000-year record of monsoonal climate, J. Asian Earth Sci., 40, 1121-1130, 2011.

Liu, D. B., Wang, Y. J., Cheng, H., Edwards, R. L., and Kong, X. G.: Cyclic changes of Asian monsoon intensity during the early midHolocene from annually-laminated stalagmites, central China, Quaternary Sci. Rev., 121, 1-10, 2015.

Liu, Y. H., Hu, C. Y., Huang, J. H., Xie, S. C., and Zhenghong, C.: The research of layer thickness of the stalagmite from the middle reaches of the Yangtze River taken as an proxy of the east Asian summer monsoon intensity, Quaternary Sci., 25, 228-234, 2005 (in Chinese with English Abstract).

Mariethoz, G., Kelly, B. F. J., and Baker, A.: Quantifying the value of laminated stalagmites for paleoclimate reconstructions, Geophys. Res. Lett., 39, L05407, doi:10.1029/2012GL050986, 2012.

Matthews, J. A. and Briffa, K. R.: The "Little Ice Age": Reevaluation of an evolving concept. Geografiska Annaler: Series A, Phys. Geogr., 87, 17-36, 2005.

McDermott, F., Mattey, D. P., and Hawkesworth, C.: Centennialscale Holocene climate variability revealed by a high-resolution speleothem $\delta^{18}$ Orecord from SW Ireland, Science, 294, 13281331,2001

Muangsong, C., Cai, B. G., Pumijumnong, N., Hu, C. Y., and Cheng, H.: An annually laminated stalagmite record of the changes in Thailand monsoon rainfall over the past 387 years and its relationship to IOD and ENSO, Quaternary Internat., 349 90-97, 2014.

Ogilvie, A. E. J. and Jónsson, T.: "Little Ice Age" research: A perspective from Iceland, Clim. Change, 48, 9-52, 2001.

Paulsen, D. E., Li, H. C., and Ku, T. L.: Climate variability in central China over the last 1270 years revealed by high-resolution stalagmite records, Quaternary Sci. Rev., 22, 691-701, 2003.

Proctor, C. J., Baker, A., Barnes, W. L., and Gilmour, M. A.: A thousand year speleothem proxy record of North Atlantic climate from Scotland, Clim. Dynam., 16, 815-820, 2000.

Proctor, C. J., Baker, A., and Barnes, W.: A three thousand year record of North Atlantic climate, Clim. Dynam., 19, 449-454, 2002.

Qin, X. G., Tan, M., Liu, T. S., Wang, X. F., Li, T. Y., and Lu, J. P.: Spectral analysis of a 1000-year stalagmite lamina-thickness record from Shihua Cavern, Beijing, China, and its climatic significance, The Holocene, 9, 689-694, 1999.

Shandong Provincial Bureau of Geology-Mineral: The Regional Geology Records, Beijing, China, Geological Publishing House, 1991 (in Chinese).

Shen, C. C., Edwards, R. L., Cheng, H., Dorale, J. A., Thomas, R. B., Moran, S. B., Weinstein, S. E., and Edmonds, H. N.: Uranium and thorium isotopic and concentration measurements by magnetic sector inductively coupled plasma mass spectrometry, Chem. Geol., 185, 165-178, 2002.

Shen, C. C., Cheng, H., Edwards, R. L., Moran, S. B., Edmonds, H. N., Hoff, J. A., and Thomas, R. B.: Measurement of attogram quantities of ${ }^{231} \mathrm{~Pa}$ in dissolved and particulate fractions of seawater by isotope dilution thermal ionization mass spectroscopy, Anal. Chem., 75, 1075-1079, 2003.

Shen, C. C., Wu, C. C., Cheng, H., Edwards, R. L., Hsieh Y. T., Gallet, S., Chang, C. C., Li, T. Y., Lam, D. D., Kano, A., Hori, M., and Spötl, C.: High-precision and high resolution carbonate ${ }^{230}$ Th dating by MC-ICP-MS with SEM protocols, Geochim. Cosmochim. Ac., 99, 71-86, 2012.

Soil and fertilizer workstation of Shandong Province: Shandong Soil, Beijing, China, China Agriculture Press, 1994 (in Chinese).

Tan, L. C., Cai, Y. J., Cheng, H., An, Z. S., and Edwards R. L.: Summer monsoon precipitation variations in central China over the past 750 years derived from a high-resolution absolute-dated stalagmite, Palaeogeogr. Palaeoclimatol., 280, 432-439, 2009.

Tan, L. C, Yi, L., Cai, Y. J., Shen, C. C., Cheng, H., and An, Z. S.: Quantitative temperature reconstruction based on growth rate of annually-layered stalagmite: a case study from central China, Quaternary Sci. Rev., 72, 137-145, 2013.

Tan, M.: High resolution climatic records of China and global change, Quaternary Sci., 24, 455-462, 2004.

Tan, M.: Climatic differences and similarities between Indian and East Asian Monsoon regions of China over the last millennium: a perspective based mainly on stalagmite records, Int. J. Speleol., 36, 75-81, 2007.

Tan, M., Liu, D. S., Qin, X. G., Zhong, H., Li, T. Y., Zhao, S. S., Li, H. C., Lu, J. B., and Lu, X. Y.: Prelminary study on the data from microbanding and stable isotopes of stalagmites of Beijing Shihua Cave, Carsologica Sinica, 16, 1-10, 1997 (in Chinese with English Abstract).

Tan, M., Pan, G. X., Wang, X. F., Qin, X. G., Teng, Y. Z., Song, L. H., and Lin Y. S.: Stalagmites and environment - Preliminary 
study on the formation of laminated stalagmites, Carsologica Sinica, 18, 197-205, 1999 (in Chinese with English Abstract).

Tan, M., Hou, J. Z., and Cheng, H.: Methodology of quantitatively reconstructing paleoclimate from annually laminated stalagmite, Quaternary Sci., 22, 209-219, 2002.

Tan M., Liu T. S., Hou, J. Z., Qin, X. G., Zhang, H. C., and Li, T. Y.: Cyclic rapid warming on centennial-scale revealed by a 2650 year stalagmite record of warm season temperature, Geophys. Res. Lett., 30, 1617, doi:10.1029/2003GL017352, 2003.

Wang, Y. J., Cheng, H., Edwards, R. L., An, Z. S., Wu, J. Y., Shen, C. C., and Dorale, J. A.: A high-resolution absolute-dated late Pleistocene monsoon record from Hulu Cave, China, Science, 294, 2345-2347, 2001.

Wang, Y. J., Cheng, H., Edwards, R. L., He, Y. Q., Kong, X. G., An, Z. S., Wu, J. Y., Kelly, M. J., Dykoski, C. A., and Li, X. D.: The Holocene Asian Monsoon: Links to Solar Changes and North Atlantic Climate, Science, 308, 854-857, 2005.
Wang, Y. J., Cheng, H., Edwards, R. L., Kong, X. G., Shao, X. H., Chen, S. T., Wu, J. Y., Jiang, X. Y., Wang, X. F., and An, Z. S.: Millennial- and orbital-scale changes in the East Asian monsoon over the past 224000 years, Nature, 451, 1090-1093, 2008.

Yuan, D. X., Cheng, H., Edwards, R. L., Dykoski, C. A., Kelly, M. J., Zhang, M. L., Qing, J. M., Lin, Y. S., Wang, Y. J., Wu, J. Y., Dorale, J. A., An, Z. S., and Cai, Y. J.: Timing, Duration, and Transitions of the Last Interglacial Asian Monsoon, Science, 304, 575-578, 2004.

Zhang, P. Z., Cheng, H., Edwards, R. L., Chen, F. H., Wang, Y. J., Yang, X. L., Liu, J., Tan, M., Wang, X. F., Liu, J. H., An, C. L., Dai, Z. B., Zhou, J., Zhang, D. Z., Jia, J. H., Jin, L. Y., and Johnson, K. R.: A test of climate, sun, and culture relationships from an 1810-Year Chinese cave record, Science, 322, 940-942, 2008.

Zhou, H. Y., Wang, Q., and Cai, B. G.: Typical northern type speleothem micro-layers found in stalagmite KY1 collected from Kaiyuan Cave in Shandong Province, North China, Quaternary Sci., 30, 441-442, 2010 (in Chinese). 